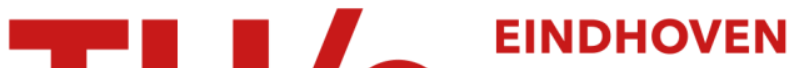 UNIVERSITY OF TECHNOLOGY
}

\section{On the bending strength of fused silica flexures fabricated by ultrafast lasers [Invited]}

Citation for published version (APA):

Bellouard, Y. J. (2011). On the bending strength of fused silica flexures fabricated by ultrafast lasers [Invited]. Optical Materials Express, 1(5), 816-831. https://doi.org/10.1364/OME.1.000816

DOI:

10.1364/OME.1.000816

Document status and date:

Published: 01/01/2011

\section{Document Version:}

Publisher's PDF, also known as Version of Record (includes final page, issue and volume numbers)

\section{Please check the document version of this publication:}

- A submitted manuscript is the version of the article upon submission and before peer-review. There can be important differences between the submitted version and the official published version of record. People interested in the research are advised to contact the author for the final version of the publication, or visit the $\mathrm{DOI}$ to the publisher's website.

- The final author version and the galley proof are versions of the publication after peer review.

- The final published version features the final layout of the paper including the volume, issue and page numbers.

Link to publication

\section{General rights}

Copyright and moral rights for the publications made accessible in the public portal are retained by the authors and/or other copyright owners and it is a condition of accessing publications that users recognise and abide by the legal requirements associated with these rights.

- Users may download and print one copy of any publication from the public portal for the purpose of private study or research.

- You may not further distribute the material or use it for any profit-making activity or commercial gain

- You may freely distribute the URL identifying the publication in the public portal.

If the publication is distributed under the terms of Article $25 \mathrm{fa}$ of the Dutch Copyright Act, indicated by the "Taverne" license above, please follow below link for the End User Agreement:

www.tue.nl/taverne

Take down policy

If you believe that this document breaches copyright please contact us at:

openaccess@tue.nl

providing details and we will investigate your claim. 


\title{
On the bending strength of fused silica flexures fabricated by ultrafast lasers [Invited]
}

\author{
Yves Bellouard* \\ Micro- \& Nano-Scale Eng., Mechanical Eng. Dept., Eindhoven University of Technology, PO Box 513, 5600 MB \\ Eindhoven, The Netherlands \\ *y.bellouard@tue.nl
}

\begin{abstract}
This paper reports on the mechanical properties of fused silica flexures manufactured by a two-step process combining femtosecond lasers exposure below the ablation threshold and chemical etching. Flexural strengths as high as $2.7 \mathrm{GPa}$ were measured, demonstrating that femtosecond lasers can be efficiently used to produce arbitrarily shaped high-strength mechanical devices, opening new opportunities for the design of monolithically integrated optomechanical devices.
\end{abstract}

(C) 2011 Optical Society of America

OCIS codes: (320.7130) Ultrafast processes in condensed matter, including semiconductors; (160.2750) Glass and other amorphous materials; (230.1150) All-optical devices; (220.4880) Optomechanics; (220.4000) Microstructure fabrication.

\section{References and Links}

1. S. T. Smith, Flexures (Gordon and Breach, 2000).

2. K. M. Davis, K. Miura, N. Sugimoto, and K. Hirao, "Writing waveguides in glass with a femtosecond laser," Opt. Lett. 21(21), 1729-1731 (1996).

3. S. Nolte, M. Will, J. Burghoff, and A. Tuennermann, "Femtosecond waveguide writing: a new avenue to threedimensional integrated optics," Appl. Phys., A Mater. Sci. Process. 77(1), 109-111 (2003).

4. A. Szameit, D. Blömer, J. Burghoff, T. Schreiber, T. Pertsch, S. Nolte, A. Tünnermann, and F. Lederer, "Discrete nonlinear localization in femtosecond laser written waveguides in fused silica," Opt. Express 13(26), 1055210557 (2005), http://www.opticsinfobase.org/abstract.cfm?URI=oe-13-26-10552.

5. C. Mauclair, G. Cheng, N. Huot, E. Audouard, A. Rosenfeld, I. V. Hertel, and R. Stoian, "Dynamic ultrafast laser spatial tailoring for parallel micromachining of photonic devices in transparent materials," Opt. Express 17(5), 3531-3542 (2009), http://www.opticsinfobase.org/abstract.cfm?URI=oe-17-5-3531.

6. G. Della Valle, S. Taccheo, R. Osellame, A. Festa, G. Cerullo, and P. Laporta, " $1.5 \mu \mathrm{m}$ single longitudinal mode waveguide laser fabricated by femtosecond laser writing," Opt. Express 15(6), 3190-3194 (2007), http://www.opticsinfobase.org/oe/abstract.cfm?URI=oe-15-6-3190.

7. L. Canioni, M. Bellec, A. Royon, B. Bousquet, and T. Cardinal, "Three-dimensional optical data storage using third-harmonic generation in silver zinc phosphate glass," Opt. Lett. 33(4), 360-362 (2008).

8. M. Beresna, M. Gecevicius, P. G. Kazansky, and T. Gertus, "Radially polarized optical vortex converter created by femtosecond laser nanostructuring of glass,” Appl. Phys. Lett. 98(20), 201101 (2011).

9. Y. Cheng, K. Sugioka, K. Midorikawa, M. Masuda, K. Toyoda, M. Kawachi, and K. Shihoyama, "Threedimensional micro-optical components embedded in photosensitive glass by a femtosecond laser," Opt. Lett. 28(13), 1144-1146 (2003).

10. Y. Bellouard, A. Said, M. Dugan, and P. Bado, "Fabrication of high-aspect ratio, micro-fluidic channels and tunnels using femtosecond laser pulses and chemical etching," Opt. Express 12(10), 2120-2129 (2004), http://www.opticsinfobase.org/oe/abstract.cfm?URI=oe-12-10-2120.

11. Y. Bellouard, A. Said, M. Dugan, and P. Bado, "Monolithic three-dimensional integration of micro-fluidic channels and optical waveguides in fused silica," in Materials Research Society Symposium - Proceedings (2003), Vol. 782, pp. 63-68.

12. Y. Cheng, K. Sugioka, and K. Midorikawa, "Microfluidic laser embedded in glass by three-dimensional femtosecond laser microprocessing," Opt. Lett. 29(17), 2007-2009 (2004).

13. A. Schaap, Y. Bellouard, and T. Rohrlack, "Optofluidic lab-on-a-chip for rapid algae population screening," Biomed. Opt. Express 2(3), 658-664 (2011), http://www.opticsinfobase.org/boe/abstract.cfm?URI=boe-2-3-658.

14. Y. Bellouard, A. Said, and P. Bado, "Integrating optics and micro-mechanics in a single substrate: a step toward monolithic integration in fused silica," Opt. Express 13(17), 6635-6644 (2005), http://www.opticsinfobase.org/abstract.cfm?URI=oe-13-17-6635.

15. Y. Bellouard, A. A. Said, M. Dugan, and P. Bado, "Monolithic integration in fused silica: When fluidics, mechanics and optics meet in a single substrate," ISOT 2009 International Symposium on Optomechatronic Technologies (2009), pp. 445-450. 
16. D. Bonamy, S. Prades, C. L. Rountree, L. Ponson, D. Dalmas, E. Bouchaud, K. Ravi-Chandar, and C. Guillot, "Nanoscale damage during fracture in silica glass," Int. J. Fract. 140(1-4), 3-14 (2006).

17. F. Célarié, S. Prades, D. Bonamy, L. Ferrero, E. Bouchaud, C. Guillot, and C. Marlière, "Glass breaks like metal, but at the nanometer scale," Phys. Rev. Lett. 90(7), 075504 (2003).

18. A. Perriot, E. Barthel, G. Kermouche, G. Quérel, and D. Vandembroucq, "On the plastic deformation of sodalime glass-a Cr ${ }^{3+}$ luminescence study of densification," Philos. Mag. 91(7-9), 1245-1255 (2011).

19. R. J. Charles, "Static fatigue of glass. I," J. Appl. Phys. 29(11), 1549 (1958).

20. M. Tomozawa, "Fracture of glasses," Annu. Rev. Mater. Sci. 26(1), 43-74 (1996).

21. Y. S. Shiue and M. J. Matthewson, "Apparent activation energy of fused silica optical fibers in static fatigue in aqueous environments," J. Eur. Ceram. Soc. 22(13), 2325-2332 (2002).

22. Y. Bellouard, Microrobotics: Methods and Applications (Taylor \& Francis / CRC Press, 2009).

23. C. B. Ling, "On the stresses in a notched strip," J. Appl. Mech. 19, A141-A152 (1952).

24. J. M. Paros and L. Weisbord, "How to design flexure hinges," Mach. Des. 37, 151-157 (1965).

25. S. Kiyama, S. Matsuo, S. Hashimoto, and Y. Morihira, "Examination of etching agent and etching mechanism on femotosecond laser microfabrication of channels inside vitreous silica substrates," J. Phys. Chem. C 113(27), $11560-11566$ (2009).

26. C. Hnatovsky, R. S. Taylor, E. Simova, V. R. Bhardwaj, D. M. Rayner, and P. B. Corkum, "Polarizationselective etching in femtosecond laser-assisted microfluidic channel fabrication in fused silica," Opt. Lett. 30(14), 1867-1869 (2005).

27. B. A. Proctor, I. Whitney, and J. W. Johnson, "The strength of fused silica," Proc. R. Soc. Lond. A Math. Phys. Sci. 297(1451), 534-557 (1967).

28. C. R. Kurkjian, P. K. Gupta, and R. K. Brow, "The strength of silicate glasses: what do we know, what do we need to know?" Int. J Appl. Glass Sci. 1(1), 27-37 (2010).

29. C. P. Chen and T. H. Chang, "Fracture mechanics evaluation of optical fibers," Mater. Chem. Phys. 77, 110-116 (2003).

30. G. Brambilla and D. N. Payne, "The ultimate strength of glass silica nanowires," Nano Lett. 9(2), 831-835 (2009).

31. L. G. Baikova and V. P. Pukh, "The effect of the type of chemical treatment on the strength of silica and silicate glasses," Glass Ceram. 12, 17-18 (1973).

32. D. Hull, Fractography, Observing, Measuring and Interpreting Fracture Surface Topography (Cambridge Univ. Press, 1999), ISBN 0521640822.

33. D. Hull, "The effect of mixed mode I/III on crack evolution in brittle solids," Int. J. Fract. 70(1), 59-79 (1995).

34. J. F. H. Custers, "Plastic deformation of glass during scratching," Nature 164(4171), 627-627 (1949).

35. K. E. Puttick, M. R. Rudman, K. J. Smith, A. Franks, and K. Lindsey, "Single-point diamond machining of glasses," Proc. R. Soc. Lond. A Math. Phys. Sci. 426(1870), 19-30 (1989).

36. O. E. Alarcón, R. E. Medrano, and P. P. Gillis, "Fracture of glass in tensile and bending tests," Metall. Mater. Trans. A 25(5), 961-968 (1994).

\section{Introduction}

Flexures are essential mechanical elements commonly used in precision and microengineering to precisely guide the motion between mechanical bodies (several books have been published on the topic, see for instance [1]). They consist of combinations of slender, continuous bodies that deform elastically upon the application of a force. Flexures are used in replacement of traditional, multi-part mechanical joints which are sensitive to friction, wear and inaccuracies resulting from assembly errors and which cannot be easily miniaturized.

Due to stringent breaking strength requirements and design constraints, flexures are commonly made out of non-transparent materials, hindering their use in miniaturized optics in general and for integrated optomechanics in particular. Here, we report on the mechanical properties of transparent flexures made out of fused silica processed by femtosecond laser and demonstrate that high flexural strength can be achieved, opening new opportunities for the design of monolithically integrated optomechanical devices.

Recent progress in femtosecond laser micromachining of fused silica have made possible the fabrication of integrated optics (from first demonstrations [2,3] to complex integrated optical systems [4-6]), optical data storage [7], new optical components [8,9], microchannels [10], and a combination of both [11-13], and all-glass optomechanical devices [14]. Thanks to the broad number of functions that can be integrated in a single piece of material $[14,15]$, fused silica processing with femtosecond laser has become the ideal platform for monolithic integration. Despite our first demonstration of optomechanical devices [14], little is known about the behavior of fused silica micromachined mechanical components. 
Fused silica $\left(\mathrm{a}-\mathrm{SiO}_{2}\right)$, the amorphous phase of $\mathrm{SiO}_{2}$, is one of the most common high quality optical substrates transparent to a broad spectrum (from about $170 \mathrm{~nm}$ to above 2.5 $\mu \mathrm{m})$. It is inert to most chemicals, which also makes it a material of choice for broad biological studies. Although counter-intuitive at first, fused silica is an attractive material for

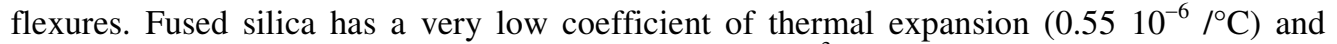
resists thermal shocks. It has a low density $\left(2200 \mathrm{~kg} / \mathrm{m}^{3}\right)$ and a Young modulus (72 GPa) comparable to that of aluminum alloys.

Fused silica is a brittle material, at least down to a certain length scale where a 'microductile' behavior is observed [16-18]. It fractures according to the weakest-link model, i.e. the point where a flaw, acting as stress concentrator, can cause the nucleation of a crack, will fail first. Its breaking strength is therefore dictated by the presence and type of surface flaws rather than by the intrinsic strength of the $\mathrm{Si}-\mathrm{O}$ bonds (which are particularly strong). The fracture toughness $\mathrm{K}_{\mathrm{Ic}}$ of the material (which measures its resistance against crack propagation) is low: between 0.5 to $1 \mathrm{MPa}^{1 / 2}$, i.e. about 20 to 50 times less than common metals. Like other glass, fused silica is also prone to static fatigue under constant loading due to stress-corrosion effects, i.e., spontaneous crack growth leading to a reduction of the fracture strength in the presence of moisture (see [19], or [20] for a general review). However, these effects can be significantly reduced and controlled by using protective polymer coatings, as is commonly done for optical fibers (for instance, in [21]) or by chemical treatment that induces 'blunt' crack tips [20]. Although fused silica is intrinsically one of the strongest materials, its use as a mechanical element has been limited by the absence of a suitable machining technique that is capable of generating any profile while preventing or minimizing the formation of surface flaws. This paper aims at demonstrating that femtosecond laser combined with chemical etching fulfills this requirement.

The first part of this paper introduces the test specimen design and an analytical model to estimate the stress level in the flexure. Photoelasticity is used to test the validity of model and to investigate in real time the stress distribution in the material. The second part reports on fracture experiments and on a fractography analysis of two representative specimens. Lastly, a topography analysis is presented, followed by a summary of our observations.

\section{Design and fabrication}

\subsection{Analytical model}

In this study, we focus on notch hinges that are an essential and representative building block for flexures-based micro-mechanism [22]. An example of complex flexure design made in silica using notch hinges can be found in [14].

Our test specimen is depicted in Fig. 1. The flexure is loaded by moving a cylindricalcontact point near the flexure end along the $\mathrm{Y}$-axis (i.e. perpendicular to the hinge longitudinal axis). As the rigid contact point translates along the $\mathrm{Y}$-axis, it is free to slide on the flexure. 

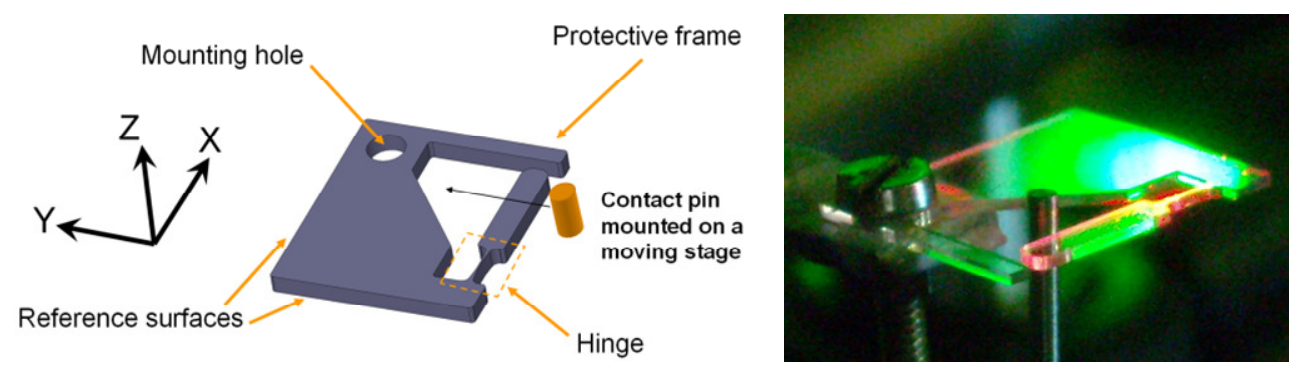

Fig. 1. Left: Schematic (CAD model) of the test structure used in these experiments. The part is cut out of a 1mm-thick fused silica substrate. It consists of a slender part (the hinge) in the lower right corner, a protective frame, reference surfaces and mounting hole in the upper left corner. A contact pin moving along the Y-axis is used to load the hinge in bending. Right: Picture of hinge about to be loaded. The contact pin $(0.5 \mathrm{~mm}$ in diameter) can be seen as well as scattered light (red) from the laser-beam used for the photoelasticity measurements that will be discussed laser in this document.

In a first approximation, the loading case is similar to a pure bending mode (the pin is sliding onto the bar that extends the flexure). Considering the elastic properties of the glass, the stress distribution inside the hinge can be calculated using classical plane-strain continuum mechanics. The design parameters of the hinge (i.e. curvature radius, thickness, etc) are chosen so that results from classical beam theory applies. In such conditions, the maximum stress in a notch hinge can be found in the outer layer and is given by [23]:

$$
\sigma_{\max }=6 K_{T}\left(\frac{M_{z}}{w t^{2}}\right)
$$

where $\mathrm{K}_{\mathrm{T}}$ is a stress concentration factor, $\mathrm{M}_{\mathrm{z}}$ the moment applied around the $\mathrm{z}$-axis, w and $\mathrm{t}$ the width and thickness of the hinge. The stress concentration factor for this particular geometry can be approximated by [1]:

$$
K_{t}=(1+\beta)^{\frac{9}{20}},
$$

in which $\beta$ is equal to $t / 2 \mathrm{r}$ (r being the flexure radius). In our case, the $\beta$ ratio is always smaller than 0.008 (the $\beta$ ratio for the thickest hinge considered in these experiments, i.e. a thickness of 107 microns for a radius of $7 \mathrm{~mm}$ ). Therefore, a reasonable approximation is to consider $\mathrm{K}_{\mathrm{t}}$ $\approx 1$ and as a consequence to neglect the stress concentration factor. Note that the expression (1) becomes similar to the classical Navier equation that gives the stress in a slender beam submitted to a bending action. In practice, as will be further described in the experimental section, to know the maximum stress applied on a flexure, we measure the beam deflection angle from its rest position.

An approximate analytical expression of the angular momentum as a function of the angular deflection was derived by Paros and Weisborg [24]:

$$
K_{\alpha_{z}, M_{z}}=\frac{M_{z}}{\alpha_{z}} \simeq \frac{2 E w t^{\frac{5}{2}}}{9 \pi \sqrt{r}},
$$

where $\mathrm{E}$ is the Young modulus, $\mathrm{w}, \mathrm{t}$ and $\mathrm{r}$ are respectively the width, the thickness and the radius of curvature for the hinge. $\mathrm{M}_{\mathrm{z}}$ is the moment applied around the $\mathrm{z}$-axis and $\alpha_{\mathrm{z}}$ the corresponding angular deflection. 
This approximation remains accurate within $5 \%$ for $\mathrm{t} / \mathrm{r}$ ratio smaller than 0.2 . In the flexures considered in this paper, this ratio is at most 0.0143 . Therefore, the approximation made is negligible.

Combining Eqs. (1) and (3), one gets the expression of the maximum stress as a function of the deflection angle:

$$
\sigma_{\max } \simeq \frac{4 E}{3 \pi} \sqrt{\frac{t}{r}} \alpha_{z}
$$

\subsection{Fabrication process and experimental procedures}

We use a two-step process based on femtosecond laser exposure and chemical etching of fused silica to fabricate our test specimens. This process is described in detail in [10]. First the specimen contour is written in the material by scanning a femtosecond laser beam (RegA, TiSapphire with 100 fs pulse-length at $250 \mathrm{kHz}, 50 \mathrm{X}$ focusing objective with an NA of 0.55 ). The pulse energy was $600 \mathrm{~nJ}$ on average with a scanning speed varying from 0.1 to $2 \mathrm{~mm} / \mathrm{s}$. In a second step, the specimen is dipped into a low-concentration hydrofluoric bath (typically 2.5 to 5\%) for several hours. It was shown recently that $\mathrm{KOH}$ can also be used in replacement to HF [25]. It is known that the polarization state of the beam with respect to the writing direction affects the etching rate [26]. The polarization is chosen so that the surface roughness of the cut edges is as smooth as possible. It is found that polarization perpendicular to the writing direction yields the best surface quality as well as the fastest etching rate. The roughness of the specimens further depends on the etching time, as will be discussed in the following sections.

\section{Experimental results}

\subsection{Micromachined specimens}

An SEM picture of the test structure is shown in Fig. 2. The mean peak-to-valley profile $\left(\mathrm{R}_{\mathrm{tm}}\right)$ of the surface (on the cut side) varies with the etching time, typically from 160 to $200 \mathrm{~nm}$. In this paper, sixteen specimens are considered. Due to their size, not all the specimens could be fabricated out of the same substrate. As there is some inherent variability between substrates (and during the laser processing), in this paper, we classify the specimens by data sets labeled from 1 to 5. Each data set corresponds to specimens that have been cut out of the same substrate and with rigorously identical exposure conditions.

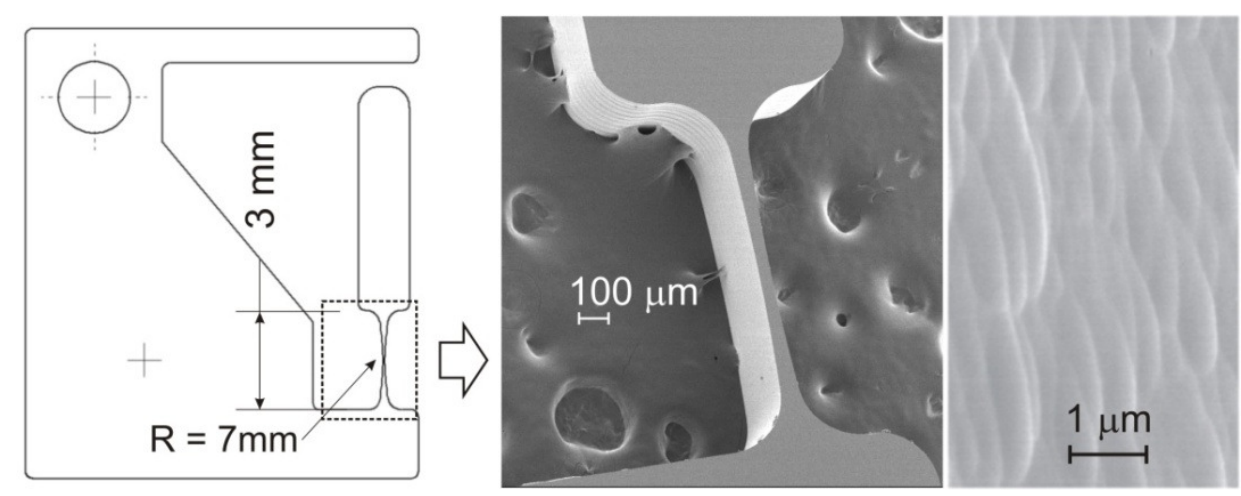

Fig. 2. (left) Specimen contour; the characteristic dimensions of the flexure are shown (Middle) Scanning Electron Microscope image of the flexure part (region framed with a dash line in the left figure) and (right) close view of the micromachined surface. Edge roughness resulting from the laser exposure typically varies from $\mathrm{R}_{\mathrm{tm}}$ (Mean peak-to-valley) $=160 \mathrm{~nm}$ to $200 \mathrm{~nm}$. 


\subsection{Beam loading}

Test structures are mounted under a microscope and loaded by pressing a contact pin translating along one axis (the Y-axis in Fig. 1) against the thicker element of the slender beam. As the contact pin touches the beam, it applies a force that elastically deforms the structure. Since there is no joint between the contact pin and the beam and considering that the pin is guided along the Y-axis, the contact points just slides along the beams as it deforms. The pin-beam contact is dry and no lubricant is used. Nevertheless the pin diameter is sufficiently large compared to the glass roughness to prevent chattering and eliminates unwanted forces along the $\mathrm{X}$ axis. This particular loading condition approximates a pure bending in the beam. The loading speed was $4+/-2 \mathrm{deg} / \mathrm{s}$ for the fracture experiments.

During the experiments, a video of the deformed beam is captured and later analyzed using image processing techniques; an example of video footage (Media 1) for a beam being loaded and unloaded is shown in Fig. 3.

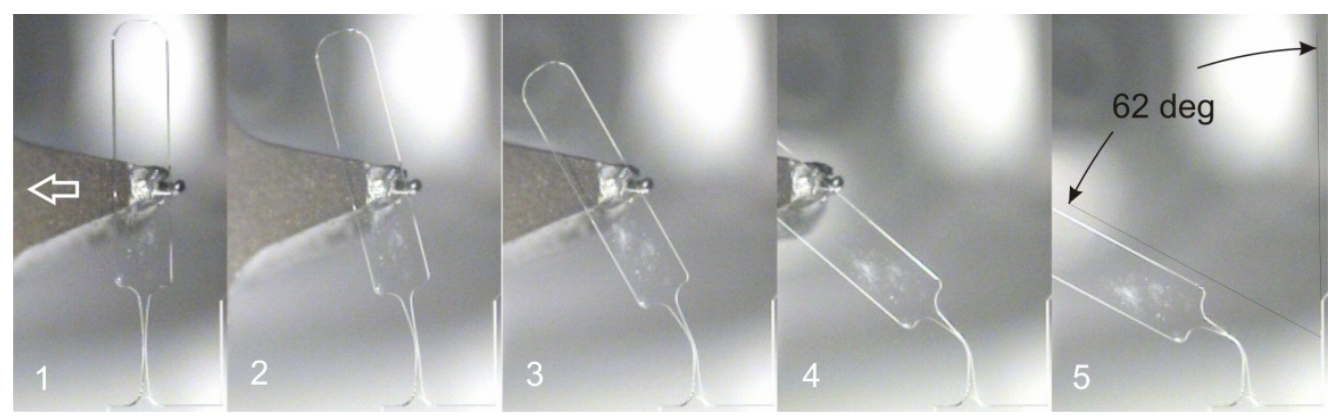

Fig. 3. Illustration of beam bending experiments. The flexure shown on these images is 40micron thick in its thinnest part and the complete beam is $9.5 \mathrm{~mm}$ long. The video shows the flexure being loaded and unloaded (see Media 1).

The example in Fig. 3 corresponds to the highest reversible bending angle obtained for the thinnest hinge tested in these series of experiments (above $60 \mathrm{deg}$ ). Despite the severe visual deformation of the hinge, we still remain within the domain of validity for the equations introduced above (i.e. the radius of curvature remains much larger than the thickness of the beam).

\subsection{In situ stress measurement using photoelasticity}

Upon bending, the stress induces birefringence in the material. This stress-induced birefringence can be used as a direct measurement of the stress state in the beam. Considering a plane strain loading case and that fused silica is isotropic, the degree of stress-induced birefringence is simply expressed by:

$$
B=\Delta n=n_{e}-n_{0}=C\left(\sigma_{y}-\sigma_{x}\right) \text { with } C=C_{1}-C_{2},
$$

where $\mathrm{C}$ is the Brewster constant and $\sigma_{\mathrm{x}}, \sigma_{\mathrm{y}}$ are the principal stresses. For fused silica, $\mathrm{C}_{1}=$ $4.210^{-12} \mathrm{~Pa}^{-1}$ and $\mathrm{C}_{2}=6.510^{-13} \mathrm{~Pa}^{-1}$.

To image the birefringence pattern, we use a simple photoelastic setup. Here, we briefly summarize its main features relevant for our practical case. We use a collimated laser beam emitted from a He-Ne laser source $(\lambda=633 \mathrm{~nm})$. The laser beam first passes through a Glanpolarizer (extinction ratio between $\mathrm{p}$ and s polarization above 10000) that sets its polarization state with respect to the flexure orientation. It then goes through the fused silica flexure and through a second Glan-polarizer (oriented $90 \mathrm{deg}$ with respect to the first one) before reaching a binocular on which a CCD camera is mounted and onto which the image of the flexure is 
formed. A characteristic interference pattern can be seen as a result of the birefringence induced by the stress applied on the beam.

The intensity of light in the imaging plane is:

$$
I(x, y)=I_{0} \sin ^{2}[2 \beta(x, y)] \sin ^{2}\left[\frac{\phi(x, y)}{2}\right],
$$

in which $\beta$ is the angle made between the birefringence axis and the polarizer and the analyzer. The intensity can be zero if this angle is 0 or $\pi / 2$. In these conditions, an observer sees isoclinic fringes, obtained when the principal stress direction coincides with the polarization. These interference fringes are independent of the stress level and can be identified by rotating the two polarizers.

The second sinus term describes the phase difference resulting from the stress-induced birefringence and can be expressed as:

$$
\phi=2 \pi C\left(\sigma_{y}-\sigma_{x}\right)\left[\frac{t}{\lambda_{0}}\right],
$$

in which $\mathrm{t}$ is the thickness of the specimen, $\lambda_{0}$ the wavelength of the light source and $\mathrm{C}$ the Brewster constant. Interference fringes are observed when (with $\mathrm{m}$ an integer):

$$
\phi=m(2 \pi) \text { i.e. }\left(\sigma_{y}-\sigma_{x}\right)=m\left(\frac{\lambda_{0}}{C t}\right) .
$$

Considering the particular geometry of our specimens (essentially along one axis), the formation of isoclinic fringes can be avoided by simply orienting the flexure with an angle $\beta$ of $45^{\circ}$ with respect to the crossed polarizers. Note that the isoclinic fringes can also be suppressed by adding two circular polarizers to the setup. Figure 4 shows a typical video capture (Media 2) of a photoelastic experiment performed on one of these flexures. In this example, the still image in Fig. 4 corresponds to the flexure just before it breaks. We note the symmetry of the isochromatic fringes along the middle axis. This is expected considering the loading mode of the flexure and validates our hypothesis of a quasi-pure bending loading mode (i.e. the stress is symmetrically distributed along the central axis for small deformation). The curvature of the fringes is slightly asymmetric with respect to the hinge center. This observation results from the fact that the hinge is clamped on one side and reflects the (expected) effect of the anchoring point in the stress distribution.

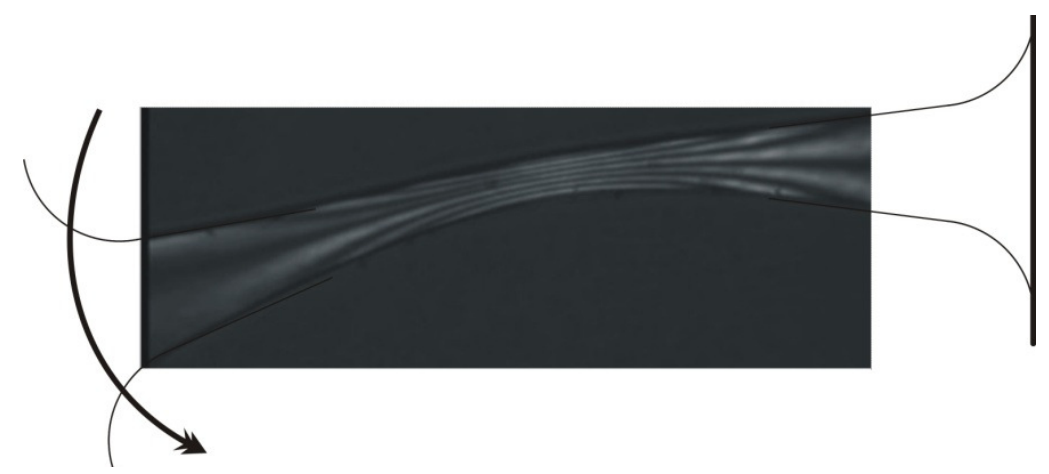

Fig. 4. Stress induced interference fringes observed in a 106 micron-thick flexure (see Media 2) - The image shows the hinge just before breaking. Counting the fringes from the center gives a direct observation of the stress effectively present in the beam. The loading mode and boundary conditions are outlined. 
Simply counting the fringe from the middle of the hinge toward the edge gives us a direct indication of how high the stress in the beam was just before it broke. Here, we can distinguish clearly three distinct fringes and half of a fourth one. Using Eq. (8), we find that the stress reaches a maximum of $1.38+/-0.1 \mathrm{GPa}$ in this case (106 micron thick flexure). This result can be compared to the theory using Eq. (4) with the measured maximum deflection angle (measured on the image shown in Fig. 4) as a parameter. This calculus yields $1.32+/-0.06 \mathrm{GPa}$ which is in good agreement with the experiment and confirms the validity of the simplified stress model to evaluate the maximum bending stress.

\subsection{Fracture experiments}

To investigate the breaking strength of these hinges, a series of specimens were manufactured and mechanically loaded up to their breaking point. The last image captured before the breaking of the hinge is used to estimate the maximum stress in the beam before rupture. The ultimate strength of fused silica depends on experimental conditions such as temperature and humidity (in particular, due to the presence of stress-corrosion effects [20]). Our experiments were performed at ambient temperature $\left(25+/-1{ }^{\circ} \mathrm{C}\right.$, in a controlled environment that maintained the temperature constant within one degree). The humidity was around $55 \%+/-5 \%$ $\mathrm{RH}$. The loading rate considered here (on average $4 \mathrm{deg} / \mathrm{s}$ ) and the short time of the experiment (typically a few seconds) hinders possible stress-corrosion effects.

In these fracture experiments, we investigated the role of the etching time and of the designed hinge thickness (i.e. the thickness before etching). The results are shown in Fig. 5 and Fig. 6. These data correspond to five series of experiments made on flexures with a range of thickness parameters (namely, $60 \mu \mathrm{m}, 80 \mu \mathrm{m}, 100 \mu \mathrm{m}$ and two times $120 \mu \mathrm{m}$ ).

Note that the indicated stress here corresponds to the highest stress that was present in the flexure at the time it broke. The highest stress in a bending mode is found on the outer layer of the beam and for the notch hinge, near to its central portion (see Fig. 4). Figure 5 shows the maximum stress observed in the hinge as a function of the removed volume by etching (left) and as a function of the final hinge thickness after etching (right). Linear fits for each series of data are shown as eye-guides. Figure 6 shows the position of the fracture surface along the hinge axis; the origin is taken where the hinge is clamped.

\#151037 - \$15.00 USD

(C) 2011 OSA
Received 13 Jul 2011; revised 28 Jul 2011; accepted 29 Jul 2011; published 3 Aug 2011 1 September 2011 / Vol. 1, No. 5 / OPTICAL MATERIALS EXPRESS 823 


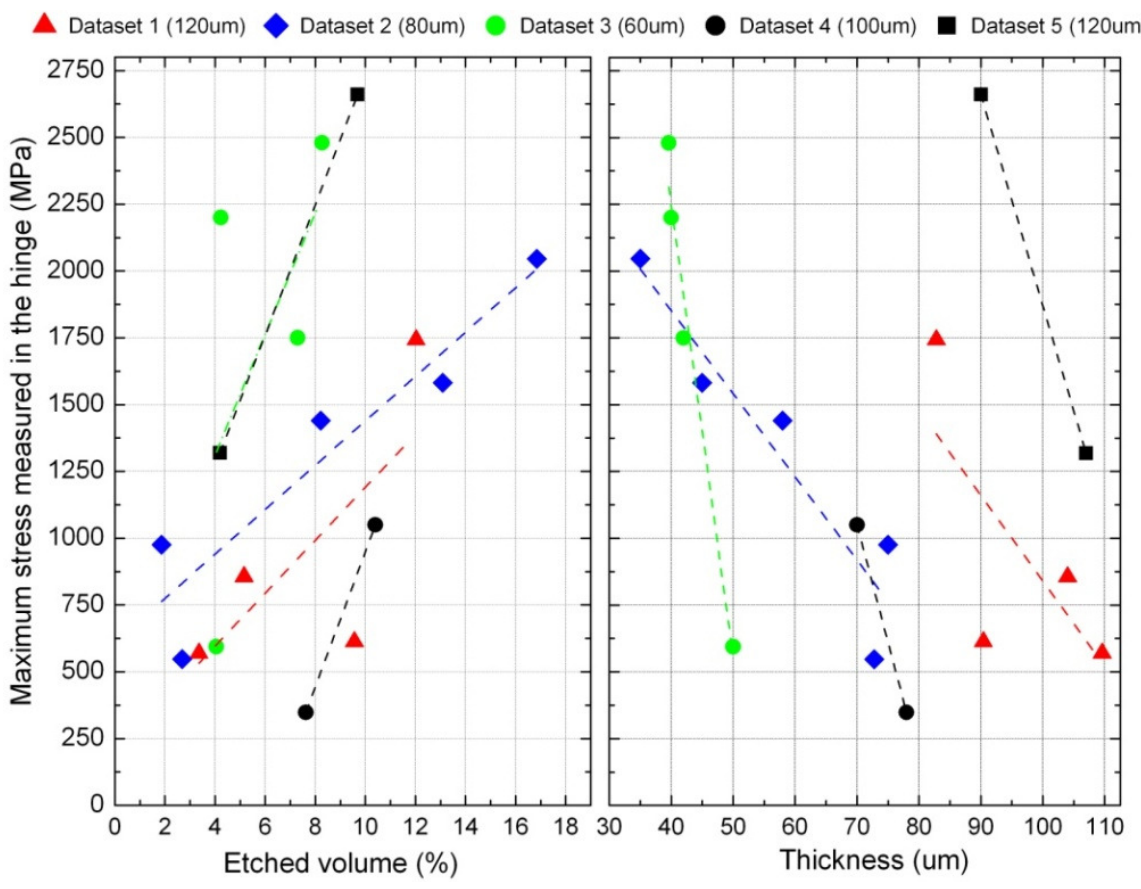

Fig. 5. Calculated breaking strength as a function of etching time and hinge thickness for five series of data with various designed thickness parameters. Note that the maximum stress does not mean it is the stress at which the glass breaks but rather the highest stress found in flexure before it broke. A maximum of $2.65 \mathrm{GPa}$ was reached with one of the specimen which is to date, the highest ever reported value for a non-pristine shape. Error bars (not shown to preserve the graph readability) are $+/-60 \mathrm{MPa}$ along de $\mathrm{Y}$ axis, $+/-0.6 \%$ for the etched volume and $+/-$ $2 \mu \mathrm{m}$ for the thickness measurement. Dotted lines are linear fits for each set of data. They are provided as eye-guides to illustrate a trend but should not be over-interpreted due to the limited number of data-points and the statistical nature of glass fracture.

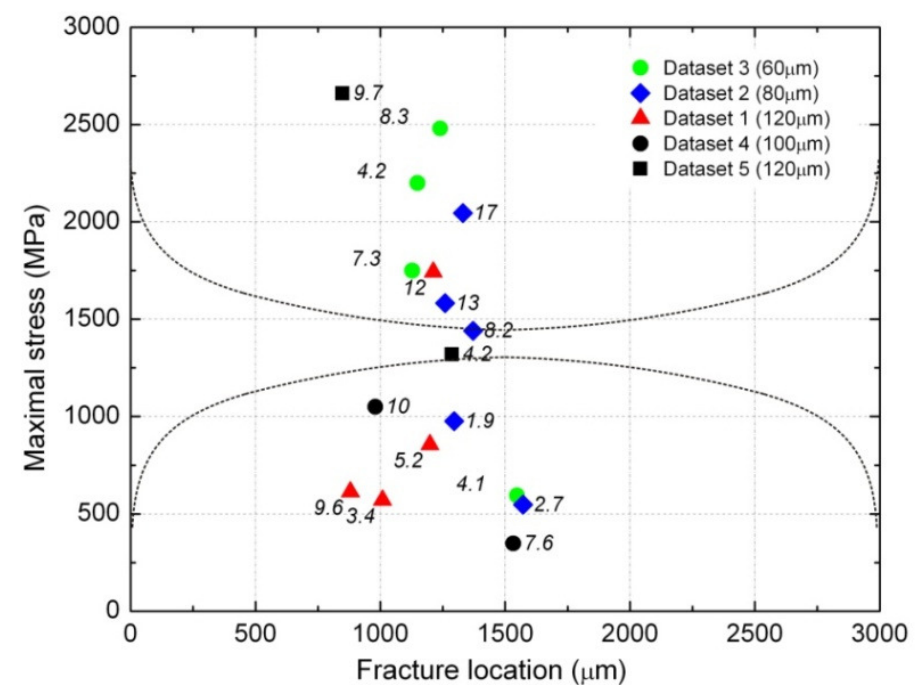

Fig. 6. Broken pattern location along the flexure profile. The origin is defined on the clamped side of the flexure. Error bars are $+/-60 \mathrm{MPa}$ for the maximum stress in the hinge and $+/-20$ $\mu \mathrm{m}$ for the fracture location. The data are shown for the same five sets of experiments shown in Fig. 5. The number next to the data point is the percentage of removed material through etching from the desired cut profile. 
This position corresponds to the longest distance from one edge of the fracture front to the hinge basis. Although the data show some spreading (which is expected considering the brittle nature of glass fracture and its statistical nature), some consistent behavior is observed:

- With the exception of one data point (out of the 15 shown here), the maximum stress always reached at least $500 \mathrm{MPa}$ which is already a factor 5 to 10 times above recommended designed value for non-pristine shapes (typically 50 to $100 \mathrm{MPa}$ ). Nine out of the fifteen reached stresses above $1 \mathrm{GPa}$, four of them above $2 \mathrm{GPa}$ and one $2.65 \mathrm{GPa}$. To the best of our knowledge, this is the highest reported strength in non pristine shapes such as fibers. At room temperature, higher reported strengths have been reported for optical fibers that have high-quality pristine surfaces (around $4 \mathrm{GPa}$ at room temperature [27-29]) and around $10 \mathrm{GPa}$ as recently been reported for nanofibers [30]). It demonstrates that femtosecond laser machining combined with etching can produce high mechanical performance flexures, and this, despite a moderate surface quality in term of roughness.

- The location of the broken surfaces shows a relative spreading of the data for the lowest estimated stress in the hinges while for the highest one, data points tend to be more concentrated in the same region. This could indicate that the occurrence of randomly distributed flaws tend to disappear with the increased etched time. It also indicates that the laser patterns are rather homogeneous in term of the modification they produce in the material.

- There is a clear trend that indicates that the higher the etched volume (and therefore, the longer the etching time), the higher the stress in the flexure can be. The average of the increase of UTS on this complete data set is $180 \mathrm{MPa} / \%$ of removed volume. It eventually reaches stress level well above $2 \mathrm{GPa}$ in three cases. Note that chemical etching enhancement of mechanical strength of glass have been reported before, for instance in glass rod specimens [31]. Although the reported experimental procedure is not clearly defined in this reference, our data nevertheless confirm these previous observations. Figure 5 left indicates that for this set of experiments, there is no obvious dependence between the maximum stress achievable and the thickness of the hinges.

- From a laser-matter interaction point of view, it shows that while laser processing most likely introduces some flaws around the laser affected zone, they are surprisingly few. Even with the minimum etching time - i.e. the time after which the flexure will be released from its substrate and the laser affected zones will have been 'dissolved' in the etchant, the mechanical strength is already substantially higher than the usual recommendation. This indicates that with low-energy pulses, the extent of 'mechanically affected zone' surrounding the laser-affected zone proper remains confined to a few microns.

- The stress distribution in the hinge is rather smooth due to the large radius of curvature of the hinge (i.e. very low stress concentration factor). This is visible in Fig. 4 where isostress lines span over large distances (several tens of microns). From the analysis of the location of the broken surfaces, we conclude that the stress level that causes the failure was close (if not equal in certain cases) to the highest calculated stress in the flexure. For the highest stress levels, the location of the broken surfaces is not exactly the middle but slightly closer to the hinge anchoring point. This is a logical and expected result. Indeed, the loading case is not exactly a pure bending. Ideally, symmetrical moments should be applied on both sides of the hinge to a have a perfect and symmetrical stress distribution with respect to the hinge center. While this is theoretically better, it is difficult to implement in practical experiments for 
complex shapes like hinges and as can be seen in these experiments, the effect of this non perfect loading conditions remains very limited.

\subsection{Fractography analysis of broken hinges}

To gain more insights on the mechanical behavior of femtosecond laser micromachined flexures, we conducted scanning electron microscope investigations of the fractured surfaces. Here, we consider specifically two specimens in which the stress reached a very high level. The specific parameters for these two hinges are shown in Table 1.

Table 1. Parameters for the Hinges Presented in Fig. 6 and Fig. 7

\begin{tabular}{|c|c|c|c|c|c|}
\hline Specimens & $\begin{array}{c}\text { Original } \\
\text { data set }\end{array}$ & $\begin{array}{c}\text { Highest stress } \\
\text { level }(\mathbf{G P a})\end{array}$ & $\begin{array}{c}\text { Fracture } \\
\text { location }(\boldsymbol{\mu m})\end{array}$ & $\begin{array}{c}\text { Design thickness } \\
(\boldsymbol{\mu m})\end{array}$ & $\begin{array}{c}\text { Removed material } \\
(\boldsymbol{\%})\end{array}$ \\
\hline Figure 6 & $\# 1$ & 1.75 & 1210 & 120 & 12 \\
\hline Figure 7 & $\# 5$ & 2.66 & 850 & 120 & 9.7 \\
\hline
\end{tabular}

Due to the rather complex geometry (square cross-section) and the bending mode, the fractography patterns show multiple facets that makes the interpretation mode complex. Furthermore, it involves numerous dynamical loading effects. Nevertheless, a few general observations can be formulated:

- In both cases, the flaw - out of which the crack leading to the failure of the hinge originated - was located on the laser micromachined surface and on the beam side submitted to tensile stress. This is not surprising considering the difference of roughness between the top (un-machined surfaces) and the side ones. It is likely that the laser introduces some flaws that will form weak points for the flexure strength. What is rather surprising is that, as can be seen in Figs. 6 and 7 and as will be further addressed in the observations related to surface quality, the hinge surface are rather rough and far from the smooth surfaces of optical fibers and yet the maximum stress was in both cases well above $1.5 \mathrm{GPa}$.

- The fractured zones are characterized by the presence of relatively large mirror surfaces in the secondary fracture fronts, (and noticeably not where the crack initially originated which possibly indicates the absence of sub-critical growth mechanism consistent with the experimental conditions) and very small and localized 'hackle' region (no 'mist' region was observed in these two specimens). River patterns are found in both specimens. These patterns are a characteristic signature of combined I/III loading mode ([32,33]); that is, a dominant crack loading force (normal to the fracture place) combined with a small shear loading mode. The morphology of river patterns provides evidence of the crack propagation directions and as such provides some clues about how the failure event unfolded.

- From the SEM observations, we can formulate the following failure scenario for both hinges. For Fig. 7, a crack opened near region \#3 and created the first fracture facet (bottom of the picture in the center) which branched upwards and propagated along labels \#4 and \#2 and in parallel, to the opposite side, i.e. on the flexure side initially under compression. At the same time a crack front may have propagated along the surface, originating from region \#3 and moving toward region \#1. In \#1, the crack front first moved perpendicular to the main micromachined plane and then changed direction due to the dynamically changing stress conditions. They eventually rejoined the second crack front moving from \#4 to \#2 within the region \#2 where these debris (of possibly densified material) are found. A similar scenario seemed to have 
happened for Fig. 8 since similar features are found. Arrows in Fig. 8 provides some indications of the possible sequence of events for this specimen.

- Both specimens have visible line features on the laser processed sides that follows the hinge contour. Three such features are clearly visible in Fig. 7 and more than 17 in Fig. 8. These features seem to be correlated to imperfections related to the scanning strategy: the complete etched profile throughout the substrate thickness is realized by stacking up the same contour multiple times across the substrate thickness. Small fluctuations in the positioning accuracy and repeatability of the stages could for instance induce these patterns. We note quite a difference of quality between the two specimens on this aspect. However, the crack seems to have originated from these manufacturing imperfections for only one of the two specimens.

- Images \#4 and \#5 in Fig. 7 and Images \#5 and \#6 in Fig. 8 show very interesting coiled filaments (or splinters) of material from about $20 \mathrm{~nm}$ to $150 \mathrm{~nm}$. Hull [33] reported the presence of splinters in river patterns in brittle materials (epoxy), but these splinters behaved as brittle material and did not show plastic flow. Here, the spiral and coiled shapes (see in particular (Fig. 7, \#5 and Fig. 8, \#4) are to our opinion, evidence of a plastic flow. These splinters are found in the river patterns, on both sides of the beam (i.e. sides that were under compressive and tensile stress). Note that coiled filaments have been reported before in single-point diamond cutting of glass [34,35], however to the best of our knowledge not in fractured facets of fused silica. The formation of these coiled splinters remains unclear at this moment but may indicate that the stress locally reached very high level combined with a rapid temperature elevation during the fast, high and sudden elastic energy release. 

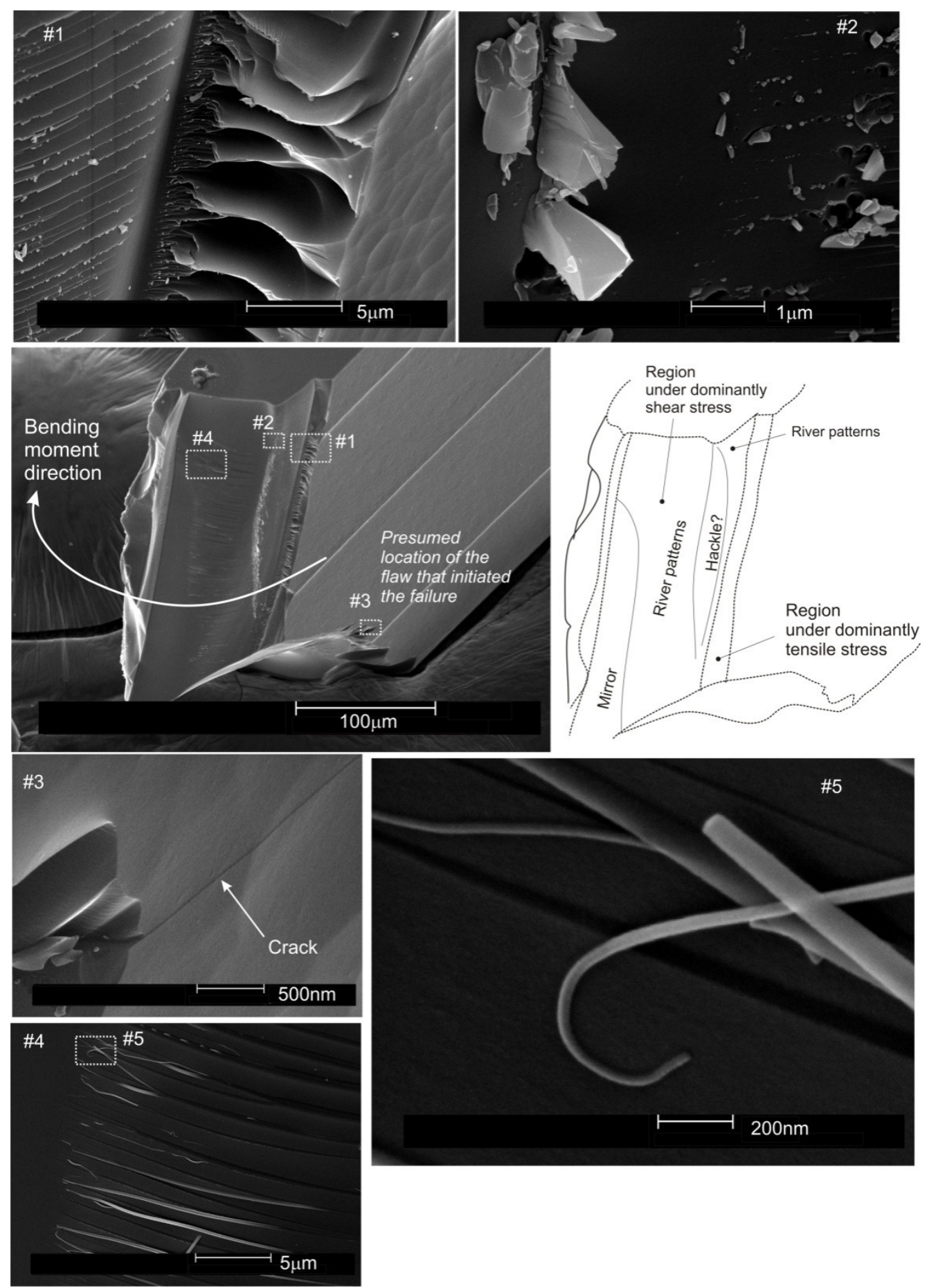

Fig. 7. Scanning electron microscopy images of the fracture zone. This specimen failed for an equivalent stress of about $1.7 \mathrm{GPa}$. The locations of images \#1 to \#5 are shown in the central image which shows an overview of the broken flexure. \#3 shows the presumed location of the flaw that initiated the catastrophic failure. \#4 and \#5 illustrate nano-scale coiled fibers found in the river pattern region. These coiled nanofibers are interpreted as evidence of localized glass plasticity. 

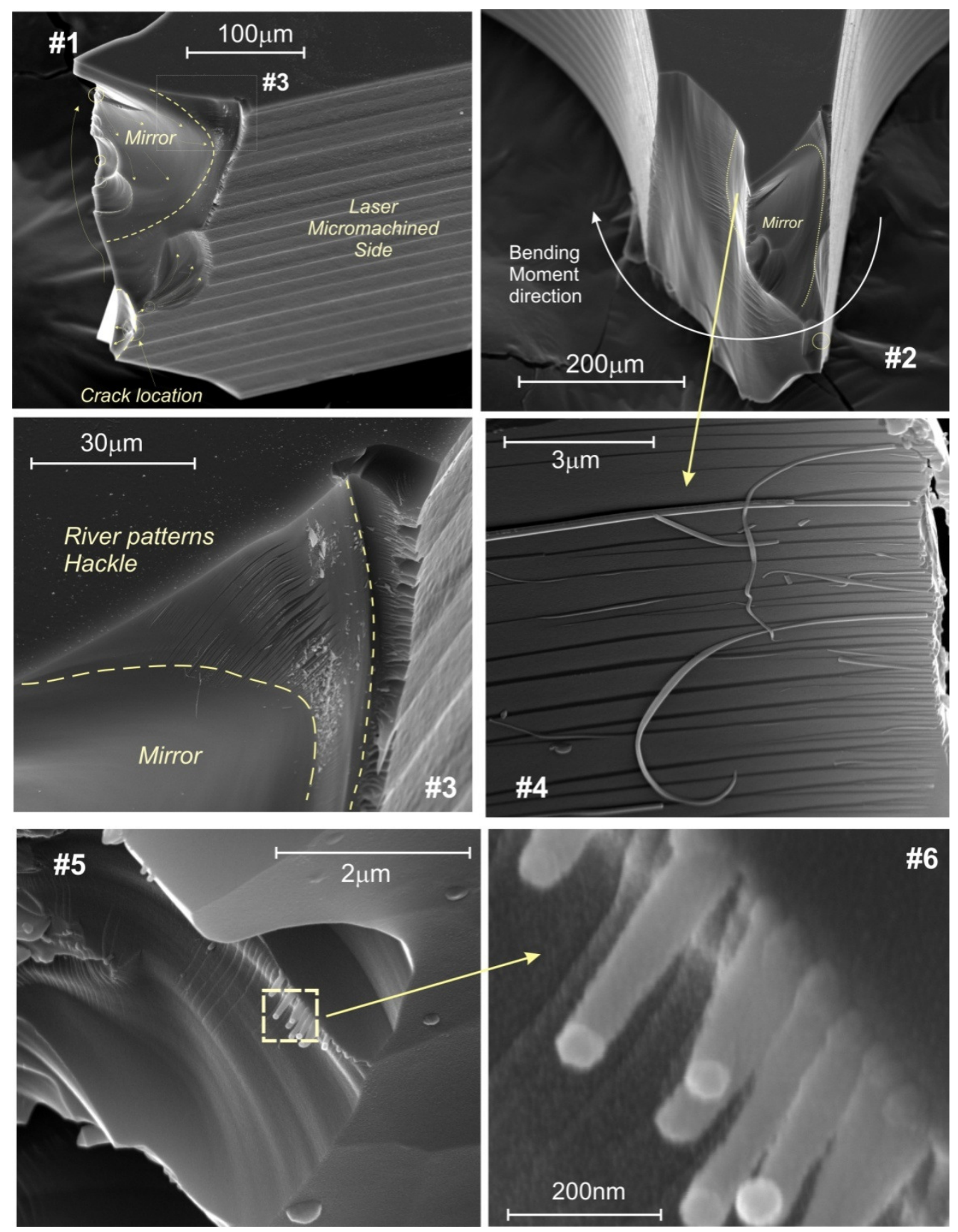

Fig. 8. Scanning Electron Microscope images of the fracture zones of a thick micro-hinge. The maximal stress reached in the hinge was well above $2 \mathrm{GPa}$. The first two images show an overview of the fracture front viewed from two different angles. Images \#3 to \#6 show salient features found in the fracture pattern. The initial crack location that is likely to have ruined the specimen is indicated in image \#1. Evidence of nanoscale plastic flow is visible in \#4.

\subsection{Topography analysis}

To further interpret the observations related to the fracture behavior (see Fig. 5) and the role of the etching rate in increasing the strength of the flexures, we performed a topography analysis of four representative specimens, fabricated out of the same substrate and laser 
machined with the exact same exposure conditions. The specimens were etched in the same etching bath $(2.5 \% \mathrm{HF})$ for increasing periods of time. The results are shown in Fig. 9.
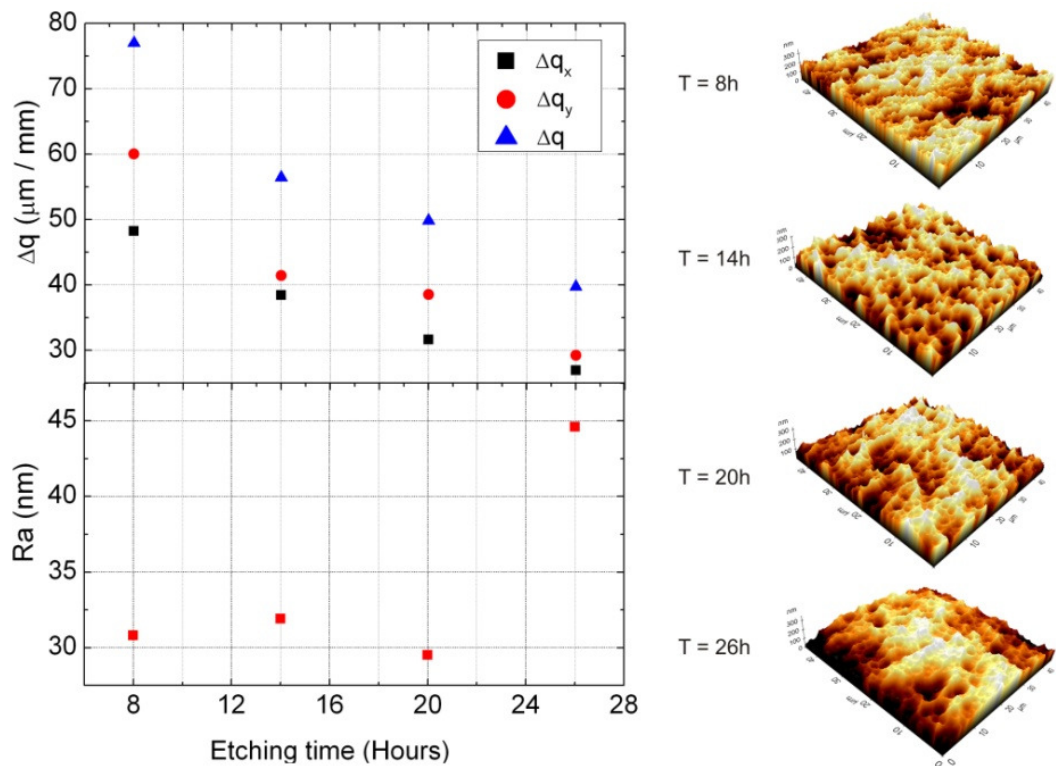

Fig. 9. Topography analysis for a series of four specimens made in the same substrate but etched for gradually increasing etching time. The top graph shows the hybrid parameter $\Delta \mathrm{q}$ that describe the geometric average slope for the entire matrix and for $\mathrm{x}$ and $\mathrm{y}$ directions. The bottom graph indicates the arithmetical mean deviation ( $\mathrm{Ra}$ ). The images on the right are the Atomic Force Microscope scans of each of the specimen. The scanned surface is 42 x $42 \mu \mathrm{m}$. The z-scale is $300 \mathrm{~nm}$.

Interestingly, we note that the roughness parameters (such as the $\mathrm{Ra}$ or the $\mathrm{Rq}$ ) seem to be not influenced by the etching time. However, the geometric average slope $(\Delta q)$ shows a quasilinear decrease with the etching time increase. This parameter is defined by:

$$
\Delta q=\sqrt{\frac{1}{L} \int_{0}^{L}\left(\frac{d y}{d x}\right)^{2} d x},
$$

in which the $\mathrm{y}(\mathrm{x})$ defines the topography profile along an axis $\mathrm{x}$ and $\mathrm{L}$ is the length of the data set considered.

The geometric average slope provides an indication related to how fast the slope on the topography profile varies along a given axis. Indirectly, it provides information related to the density of peaks contained in a given profile. As visible in Fig. 9 right, indeed the density of peaks (and the slope variation) decreases as the etching time increases although the roughness arithmetical mean deviation $(\mathrm{Ra})$ does not change consistently with the etching time. The decrease of $\Delta \mathrm{q}$ is consistent with a local decrease of stress-concentrators intensities and densities on the micromachined surface and, therefore, with a higher resistance of the material.

\section{Summary}

We demonstrated that femtosecond laser micromachining can produce high-strength mechanical components out of fused silica. Although the post-machining, the mean peak-tovalley roughness parameter $\left(R_{t m}\right)$ is relatively high (typically around $200 \mathrm{~nm}$ ), stress levels as high as $2.7 \mathrm{GPa}$ (i.e. close to the highest level achieved with pristine optical fiber surfaces) were measured in micro-hinges. In the 15 specimens measured, the breaking strength was at 
least an order of magnitude higher than the recommended design stress for fused silica part and for 14 of them, above or well above typical breaking strength values for common engineering materials. These results show that the combination of femtosecond laser exposure and chemical etching do not introduce significant surface flaws. We observe a clear dependence of the etching time (in HF bath) on the mechanical strength. Our topography analysis indicates a decrease of the average geometric slope correlated with the increase of breaking strengths. This observation suggests that post-annealing of glass that can lead to higher surface smoothness (as demonstrated for instance by Cheng et al. [9]), could eventually lead to even higher mechanical strength.

Using photoelasticity, we were able to directly observe the stress inside the material and to confirm the model we used to calculate the hinge stiffness. Fractography observations were conducted on some of the broken hinges. There, we located the crack origins and we observed evidences of plastic flow in river patterns on the fractured surface. These evidences, consisting of coiled nanofibers, further support a ductile behavior of glass fracture at the nanoscale as suggested by others $[17,18]$.

\section{Conclusion: perspective for opto-mechanics}

This study demonstrates the viability of femtosecond laser processes for the fabrication of micromechanical devices with properties at least comparable to, if not better than, most materials commonly used at the microscale. Unlike silicon which is a crystal (but can also exhibit high breaking strength comparable to our observations in glass), fused silica is isotropic and as such, offers significantly more design flexibility - as an example, the substrate orientation has no importance with respect to the part to be machined.

Fundamental studies on the strength of glass have been limited by experimental constraints. For instance, as pointed out by Alarcón et al. [36], in tensile tests, a major difficulty lies in mounting the specimen properly: fixtures used for gripping ductile materials cannot be used and classical dog-bone grips or others button-ended specimens require careful adjustment to eliminate spurious bending stresses. This has limited investigations mostly to fibers with high-quality surfaces and/or to bending modes. The flexibility of a direct process (such as we use here) makes virtually any test specimen designs possible, including specimens that contains delicate elements which need to be handled carefully before the test can take place. Femtosecond laser processing therefore offers a unique platform to investigate fundamental and unresolved issues related to the study of the strength of glass (see for instance $[17,18,20,28]$, which discuss some of these issues).

Femtosecond laser processing of fused silica combined with chemical etching offers a mean to combine integrated optics with micro-mechanics in a single monolithic substrate. As an example, we demonstrated in another work [14] that waveguides and mechanical elements can be combined in a single monolith. This work further paves the road toward increased monolithic integration where features as diverse as gratings, waveguides, mechanical flexures, and fluidic channels can be made out of a single substrate, greatly simplifying the complexity of microsystems and considerably reducing the number of fabrication steps.

\section{Acknowledgments}

The author acknowledges the help of Translume Inc. for the specimen manufacturing as well as the help of Dr. Frédéric Madani-Grasset for the surface data processing. This work is partially supported by the Femtoprint project (http://www.femtoprint.eu/) of the 7th Framework programme of the European Commission as part of the NMP / Factory of the Future initiative. 